\title{
EL PLACER “TRÁGICO” DE VOLVER A VER UN FILM: EL SABER SUPERIOR DEL ESPECTADOR EN SEGUNDOS VISIONADOS,
} REMAKES, FLASH-BACKS Y ADAPTACIONES DE HECHOS REALES

\section{THE “TRAGIC" PLEASURE IN RE-VIEWING A FILM: THE SPECTATOR SUPERIOR KNOWLEDGE IN SECOND VIEWINGS, REMAKES, FLASH-BACKS AND FILM ADAPTATIONS OF TRUE EVENTS}

\section{AUTOR}

\section{Mariona Visa Barbosa}

Investigadora. Universitat Pompeu Fabra. Barcelona (España) onavis79@yahoo.es.

\section{CURRÍCULUM VITAE}

Investigadora pre-doctoral de la Universitat Pompeu Fabra. Diploma de Estudios Avanzados (DEA) con "Les vinyetes gràfiques de Jordi Labanda", calificada con excelente en el tribunal de suficiencia investigadora de la UPF. 2006. Licenciada en Comunicación Audiovisual. Universitat Pompeu Fabra. Barcelona. 2001

\section{RESUMEN}

Este artículo analiza el rastro trágico que existe en los visionados de remakes, precuelas, adaptaciones de hechos reales, flash-backs y cuando realizamos el segundo visionado de algunas películas. Tiene como objetivo el estudio de la recepción de este tipo de obras cinematográficas, teniendo en cuenta el contexto y, en concreto, la información que el espectador tiene previamente sobre la obra que 
contempla. Un rastro trágico que en parte tiene que ver con los procedimientos estilísticos utilizados por el director, pero que se hace patente también a partir de elementos extradiegéticos o de juegos narrativos propuestos por el espectador, que el director nunca podria sospechar, o que al menos no son un objetivo prioritario a la hora de realizar la película.

\title{
PALABRAS CLAVE
}

Espectador - Tragedia - Remake - Flash-back - Adaptación

\begin{abstract}
This paper analyses the tragic trace that exists in the viewing of remakes, presequels, adaptations of true events, flash-backs and when the spectator realizes a second viewing of some films. The aim of this article is to study the reception of this kind of movies, taking into account the context and, specially, the previous information that the spectator has about the film. A tragic trace that in part comes from the stylistic procedures used by the director, but that can also proceed from extradiegetic elements or narratives games proposed by the spectator, that the director never could suspect, or that are not a priority aim at the moment of making the film.
\end{abstract}

\section{KEY WORDS}

Spectator - Tragedy - Remake - Flash-back - Adaptation

\section{ÍNDICE}

1. Introducción 
2. El saber superior del espectador en segundos visionados

3. Remakes: volver a ver de otra manera

4. El efecto catarsis de las adaptaciones de hechos reales

5. Flash-backs y precuelas: formas dramáticas que predisponen a la irrupción del sentido "trágico"

6. Conclusiones

7. Bibliografía

\section{Introducción}

La emoción que despierta el visionado de un filme se debe, en algunos casos, a elementos totalmente extradiegéticos que no son controlados por su autor $\mathrm{y}$, a veces, ni tan sólo por el espectador. Esta emoción tiene que ver con el concepto de tragedia que seguidamente será definido y con su posible aparición en ciertas formas que el espectador contemporáneo tiene de contemplar una película. Concretamente, este artículo estudiará el rastro trágico que aparece cuando los espectadores asisten a la proyección de remakes, precuelas, adaptaciones de hechos reales, flash-backs y cuando realizan el segundo visionado de algunas películas.

Este rastro trágico, que es placentero para el espectador y viene determinado por su saber superior de la historia, surgirá de forma involuntaria en los segundos visionados y en los remakes, mientras que en las adaptaciones de hechos reales, en los flash-backs y en les precuelas el director es más consciente de este efecto. A pesar de esto, veremos cómo la presencia de lo trágico en estas películas no es siempre un elemento previsto con anterioridad, sinó que se desprende de la reacción que tiene el 
espectador al ser un observador privilegiado de las historias. Por tanto, cuando hablamos de la irrupción del saber superior del espectador como determinante para la comprensión del film no será siempre desde el punto de vista narrativo o formal de la propia obra, sino intentando encontrar los elementos añadidos a posteriori que se evocan en el visionado de los filmes, teniendo en cuenta la aportación que el espectador hace entonces a la obra. Un rastro trágico que en pequeña parte tiene que ver con los procedimientos estilísticos utilizados por el director, pero que se hace patente también a partir de elementos extradiegéticos o de juegos narrativos que propone el espectador, que el director nunca podría sospechar, o que al menos no son un objetivo prioritario a la hora de realizar la película.

Así pues, el azar tiene que ver, en el caso de los remakes y segundos visionados, en la aparición del sentido trágico al contemplar una película, a pesar que desde el punto de vista histórico el azar y la tragedia son dos términos que serian antagónicos. Albin Lesky deja claro que "donde en lugar de la auténtica situación trágica aparezca el juego de la casualidad, en lugar de la experiencia consciente de la angustia existencial, el gesto de lamentación teatral, dudaremos de si hablar de auténtica tragedia." (Lesky, 2001, p.54). Para él, lo que es tragedia es asistir a la irrevocabilidad de una narración que nos habla de determinados episodios de la existencia humana.

El formato de las películas el análisis de las cuáles propone este artículo aportan este sentido de irrevocabilidad del que habla Lesky y se ha creído interesante estudiarlo a pesar que este sentido sea dado a elementos casuales, relacionados con el azar y la experiencia personal de los espectadores. 
Según Aristóteles, una tragedia es una "imitación de una acción esforzada y completa, de cierta amplitud, en lenguaje sazonado, separada cada una de las especies en las distintas partes, actuando los personajes y no mediante relato, y que mediante compasión y temor lleva a cabo la purgación de tales afecciones." (Aristóteles, 1998, p. 45).

Si nos atenemos a esta definición, el cine no es tragedia. La composición en verso, la presencia de los coros y otros elementos fundamentales según la definición exacta de tragedia no están presentes en la gran mayoría de películas.

Aristóteles también deja claro que una tragedia bien construida tiene que atenerse a la estructura correcta de los hechos, siguiendo el orden cronológico de inicio, nudo y desenlace. Por tanto, desde el punto de vista formal ya observamos que el término tragedia es muy limitado.

Pero por otro lado, el autor hace un estudio de los elementos básicos a nivel narrativo en una tragedia y de los sentimientos que estos despiertan en el espectador, y es aquí dónde encontramos el punto de similitud con la contemplación de ciertos formatos cinematográficos.

Nos referimos a lo que Aristóteles llama reconocimiento (anagnórisis). Según él, una fábula compleja es aquella en la que hay un cambio de fortuna, acompañado de un cambio de peripecia y de reconocimiento. La peripecia es el cambio de acción en sentido contrario. El reconocimiento es el paso que marca el cambio de la ignorancia al conocimiento, ya sea para bien o para mal. Esta peripecia y reconocimiento son los que despiertan los sentimientos de compasión en el espectador. Este cambio de saber 
hace referencia a los personajes, pero ¿qué sucede cuando el cambio de saber afecta a los espectadores?

En una película, los procedimientos narrativos siempre se orientan en dirección al espectador. Xavier Pérez advierte de que no hay ningún procedimiento narrativo que no se adhiera a una de estas operaciones de orden pragmático: hacer entender una historia, traspasar discursivamente una ideología, proporcionar placer. (Pérez, 1999). En mayor o menor proporción, una historia siempre comparte estos tres procedimientos, a pesar que en algunos ejemplos pueda parecer que uno de ellos eclipsa a los otros.

\section{El saber superior del espectador en segundos visionados}

En el caso de los segundos visionados de una película, se activan distintos elementos en la mente del espectador. Para empezar, no todos los filmes se disfrutan con igual intensidad la segunda vez. Algunos podrían resultar aburridísimos, como algunas historias biográficas o descriptivas.

El espectador disfruta en el segundo visionado, e incluso parece un hecho obligado realizarlo, en las películas en que el protagonista sufre un cambio de fortuna inesperado, o en aquellas en que hay "sorpresa final". Es decir, en aquellas en que hay un cambio de saber $y / o$ de peripecia que hace que la historia tome una dimensión diferente de la que tenía al inicio del primer visionado. El ejemplo de las películas El sexto sentido (M. Night Shyamalan, 1999) o El bosque (M. Night Shyamalan, 2004) es muy claro. También lo es el de Abre los ojos (A. Amenábar, 2001) 
y Los otros (A. Amenábar, 1997). En este caso, el espectador que contempla el filme por segunda vez ya no asiste a la explicación de una historia (ya la conoce), sino que disfruta del placer que le proporciona el hecho de ver una historia dónde sabe más que los protagonistas. Y como este saber superior es en estos casos muy valioso, ya que sucederán acontecimientos imposibles de descifrar por el resto de espectadores, su placer es todavía superior. Lo que hace interesante el segundo visionado es el reconocimiento, el cambio de saber que se ha operado en los espectadores, que ahora conocen cuál es la resolución de los hechos.

Aristóteles dijo que una buena fábula es aquella que pasa de la felicidad a la infelicidad, y no por maldad del personaje sino por una fatalidad. Como remarca Albin Lesky, "lo que hemos de sentir como trágico debe significar la caída desde un mundo ilusorio de seguridad y felicidad a las profundidades de una miseria ineludible."(Lesky, 2001, p.45). Si el hecho de contemplar una historia por segunda vez contiene ya muchos elementos trágicos, estos aumentan cuando la historia que se contempla es una historia trágica. Lesky dice que siempre tiene que haber alguien que sea testimonio de esta tragedia, así todo tiene un sentido. El hecho de darse cuenta de las cosas forma parte de la tragedia, es un elemento constitutivo del efecto que se busca. Por tanto, los espectadores que asisten al segundo visionado de una historia o contemplan aquello que ya saben, pasan por este estado de resignación, de saber que el destino ya está marcado y que ningún elemento será dejado al azar.

\section{Remakes: volver a ver de otra manera}

En el caso de los remakes, las nuevas filmaciones de películas ya existentes, el placer que siente el espectador es similar, pero con algunos matices distintos. Hay 
elementos similares, ya que en los remakes también se conoce la historia, ya se ha visto en una versión anterior. Por tanto el procedimiento de transmisión de información no será prioritario. Pero en los remakes se hace presente el elemento del suspense, que no existía en el caso de los segundos visionados. A pesar que el espectador ya conoce a grandes rasgos la narración, es posible que no la recuerde con exactitud, puede ser que con el tiempo haya olvidado algunas partes de la historia, aún sabiendo el desenlace final. Siguiendo las palabras de Noël Carroll, el espectador conocería en este caso la respuesta a las macrocuestiones (aquellas preguntas que se resuelven al final de la película), pero habría olvidado la respuesta a algunas microcuestiones (preguntas que se resuelven en el interior de una sola secuencia). De esta manera, puede contemplar la película con el poder que otorga el hecho de conocer la respuesta a aquellos hechos más inquietantes y decisivos, y a la vez disfrutar del pequeño suspense que proporciona el no saber cómo se resuelven ciertas cuestiones menos importantes de la acción.

Otro elemento de suspense en los remakes tiene que ver con el interés que el espectador puede tener al ver ciertas escenas que la censura (por su contenido violento o erótico) hubiera hecho desaparecer de la versión anterior. En este caso, el remake contemporáneo hace posible que el espectador pueda ver aquella escena de la que se le privó en la primera película. De la misma manera, también actúa el suspense para ver cómo nuevos actores interpretan a los personajes y para ver cómo se ha llevado a cabo la puesta en escena de ciertas secuencias que el espectador guarda vivas en la memoria.

A pesar de lo que hemos dicho, no creemos que sean sólo estos pequeños elementos de suspense los que hacen que el público asista a ver los remakes. ¿Por qué, sino, hubo espectadores que asistieron al remake (o mejor dicho recreación) que Gus Van 
Sant hizo de Psicosis (1998), cuando ya se sabia que había repetido plano a plano el original de Hitchcock? En este caso, la diferencia entre remake y segundo visionado es escasa. Creemos que, al igual que el director dice que filmó esta película como un ejercicio de estilo y no con voluntad de explicar una historia, el espectador asistía a las salas atraído por este juego visual más que para vivir una historia. Eran pocos los espectadores que, en el año 1998, no conocían la escena en que Janet Leigh moría asesinada en la ducha. El conocimiento de este hecho da un valor nuevo a toda la primera parte del filme, por tanto se crea una sensación gratificante al saber más que el personaje, al observar cómo el personaje de Marion Crane está atormentado por unos problemas que pronto parecerán fútiles y preparando una huída que el espectador ya sabe que no la llevará a ninguna parte.

\section{El efecto catarsis de las adaptaciones de hechos reales}

El caso de las adaptaciones de hechos reales comparte parte de lo que hemos dicho hasta ahora, con algunas particularidades. Normalmente es necesario un cierto tiempo entre el acontecimiento y la adaptación cinematográfica, sobretodo cuando los hechos son dolorosos. En el caso de los atentados del 11-S, fue cuatro años después cuando Oliver Stone anunció su interés en llevar los acontecimientos a la gran pantalla. Por tanto, se puede dar el fenómeno de la catarsis, dónde a través de una purga psicológica los espectadores liberan los sentimientos dolorosos y toman consciencia de aquello que sucedió. Se trata de asistir al relato de unos hechos que sabemos cómo acaban, pero por ser reales se crea un efecto trágico ya que se asiste la asimilación de un relato por parte de los propios testimonios que vivieron o que saben que sus contemporáneos o antepasados vivieron. 
También existe el caso de los relatos de proezas heroicas o el de biografías de personajes famosos, a pesar de que éstas quedan desprovistas del efecto trágico explicado en el párrafo anterior. Aquí entra en juego el querer saber cómo son en su vida privada (a pesar de ser una especulación), de saber cómo actuaron los personajes históricos. Es el voyeurismo inherente en todo espectador el que aporta éxito a este tipo de películas.

\section{Flash-backs y precuelas: formas dramáticas que predisponen a la irrupción del sentido "trágico"}

En la gran mayoría de películas, la inserción de flash-backs es un recurso utilizado para la simple transmisión de información sobre el pasado de los personajes. En estos casos el principio de placer puede quedar hasta anulado, ya que se nos da información que puede estar muy alejada de la historia que se nos cuenta en la película. Pero el espectador acepta el trámite ya que sabe que la información que obtendrá será valiosa. Durante unos minutos en el caso de los flash-backs o de toda la película en el caso de filmes que se estructuran completamente en un flash-back, no importa tanto lo que pasa (ya se sabe o se intuye porque al principio se ha contemplado el desenlace), sino cómo pasa. Este viaje al pasado de los personajes aumentará el saber del espectador, por tanto, si se da al inicio de la película, el resto del visionado tomará el cariz trágico que antes hemos explicado.

Muy a menudo las actuaciones del pasado, ya sean las propias o las de familiares próximos (la tragedia también se hereda) marcan el destino del personaje protagonista. Los protagonistas de estas películas tienen por tanto algunas similitudes con los "hombres trágicos" nacidos en la escena teatral de Atenas del 
siglo V. Como dice Jean- Pierre Vernant, "el héroe deja de ser el modelo que era en la epopeya y en la poesía lírica: se ha convertido en el problema".(Vernant, Vidal Naquet; 2002, p.82)

El mismo desorden cronológico de la estructura en flash-backs o de la estrena desordenada de filmes episódicos (que sería el caso de las precuelas) apunta a tragedia. Como si el distinto tiempo de los hombres (personajes) y los dioses (en este caso, espectadores) provocara una nueva consciencia que muestra la verdad en su más trágica consecuencia. Normalmente cuando las películas se inician, todo está ya decidido, aunque nadie lo sepa. Pero cuando la representación de las películas empieza por el final, el espectador ya sabe que todo está decidido y de qué manera. Tiene un conocimiento más alto que el de los personajes y eso le lleva a contemplarlos con la superioridad propia de los dioses que lo dominan todo. Es una elección del director o del guionista, que, cuando ha terminado de escribir el argumento tiene que decidir qué llevará al escenario, en qué orden, en qué escala. Hay que decidir qué deja fuera de campo, cuál será el inicio, el orden y la duración. El dramaturgo siempre ha controlado la representación de la obra para controlar la respuesta del auditorio. (Olson, 1985). Tiene que determinar qué es aquello que el auditorio tiene que saber en un momento dado a fin de dirigir sus sentimientos. Según qué conocimientos tenga el espectador, sus emociones variaran. Es una manera de situar al auditorio en una situación mental que lo predisponga a una determinada emoción. Como dice Elder Olson, si se utiliza una forma dramática dada es en cierta manera para proponer la obtención de un tipo de respuesta, utilizar una forma trágica es proponer la llamada de un efecto trágico. En este caso tenemos por tanto un ejemplo distinto al de los remakes, adaptaciones de hechos reales o segundos visionados ya que en los flash-backs o precuelas hay la voluntad por parte del autor de conseguir este efecto. 
El éxito en los últimos años de las precuelas de La guerra de las galaxias (La venganza de los Sidh) (G. Lucas, 2005) o de Batman (Batman Begins) (C. Nolan, 2005) son un claro ejemplo de como el procedimiento de la proporción de placer no queda anulado por el de la simple transmisión de información, ya que el rastro trágico otorga al espectador una posición superior a la de los personajes.

\section{Conclusiones}

Hemos visto, pues, como el espectador disfruta estos visionados en un sentido diferente a como fueron concebidas las películas, por el hecho de su saber superior respecto a los personajes. Alfred Hitchcock dejaba claro en su libro de entrevistas con François Truffaut la diferencia entre el suspense y la sorpresa. (Truffaut, 1997, p. 61). Mientras que la sorpresa es un hecho que tanto los personajes como el espectador desconocen (Ej.: la explosión inesperada de una bomba), el suspense se da cuando los espectadores saben más que los personajes (Ej.: mostrar un plano de la bomba unos minutos antes de la explosión). Con la sorpresa se consiguen unos segundos de entretenimiento, mientras que el suspense proporciona unos cuantos minutos de placer al público. Por tanto, si el público disfruta cuando sabe más que los personajes, es lógico que muchos espectadores encuentren interesante el visionado de las películas antes comentadas. A pesar de esto, esta claro que es un efecto que tiene una extensión limitada, y del que no se puede abusar, ya que el visionado repetitivo dejaría sin sentido este sentimiento. 
Otro elemento por el que tienen éxito estas películas es por el hecho que el espectador se apiada de los personajes, siente compasión por ellos ya que están sometidos a un destino del que no pueden escapar. Unos de los elementos básicos en toda tragedia es la presencia de la fatalidad: nada puede hacerse para parar aquello que ha predicho el oráculo. Cuando este destino irreversible hacia el que se dirige el protagonista es conocido por el espectador, el desenlace actúa como una forma de oráculo que lleva a los personajes a vivir una acción que no podrán cambiar.

El espectador siente compasión ante la presencia de elementos tristes y dolorosos, que sean destructivos; o de elementos que puedan causar ruina o también ante aquellos grandes males que dependen de la fortuna. Se experimenta el concepto de aquello trágico cuando el espectador se siente afectado en su interior, cuando se intuye que todo aquello que se explica tiene o puede tener una relación con nuestro mundo.

Así pues, el concepto de tragedia implica que las acciones que contempla el espectador serán negativas, catastróficas. Por tanto, la contemplación por parte de los espectadores se convierte en compasión hacia un personaje destinado irremediablemente a caer en el abismo. A menudo aquello que lleva a los héroes a la tragedia es su coraje (que proviene de "corazón", fuente de pasiones nobles como la justa cólera). Nada podría hacer evitar este desenlace. Y el hecho de que los personajes hayan actuado con coraje les atorga un aura de divinidad. No podría ser de ninguna otra manera, a pesar que el espectador lo contemple con el corazón encogido, sabe que el héroe no podía hacer otra cosa. Tampoco esperaba menos de él. 
Pero, ¿cómo es posible que el placer pueda surgir de la contemplación de una tragedia? Elder Olson dice que las ficciones nos emocionan aún y tener muchas cosas desagradables y hasta dolorosas desde el punto de vista natural, y que a pesar de ello nos gusta emocionarnos de esta manera ya que las cosas dolorosas devienen agradables. (Olson, 1985, p. 136)

Claro que la compasión que se suscita aquí es una forma nueva, y según Aristóteles no tiene mucho valor: "El temor y la compasión pueden nacer del espectáculo, pero también de la estructura misma de los hechos, lo cual es mejor y de mejor poeta." (Aristóteles, 1998, p. 173).

El efecto trágico al que hemos hecho referencia en este artículo es, por tanto, un efecto "menor" (a excepción del utilizado en flash-backs y precuelas) que no proviene de los recursos utilizados por los directores ni del formato. Se trata simplemente de explotar al máximo la posibilidad que tiene el espectador de disfrutar de un efecto secundario que le proporciona su afición al cine.

\section{Bibliografía}

ARISTÒTIL. (1998) Retòrica. Poética. Ed. 62. Barcelona.

LESKY, ALVIN. (2001) La tragedia griega. Quaderns crema. Barcelona.

FESTUGIÈRE, André-Jean. (1986) La esencia de la tragedia griega. Ariel Filosofía. Barcelona.

OLSON, Elder. (1985) Tragedia i teoria del drama. Quaderns Crema. Barcelona PÉREZ, Xavier. (1999) El suspens cinematogràfic. Ed. Pòrtic. Barcelona.

TRUFFAUT, François.(1997) El cine segun Hitchcock. Alianza Editorial. Madrid. 
VERNANT, Jean Pierre; VIDAL-NAQUET, Pierre. (2002) Mito y tragedia en la Grecia antigua. (2 vol). Paidós. Barcelona.> 